\title{
STORY TELLING AND ITS RELATION WITH FILM SCRIPT
}

\author{
Reem Lotfy Mahmoud SAAD *
}

Faculty of Arts \& Design, Pharos University, Egypt

\begin{abstract}
Storytelling is a method of communication based on a narrative structure of discourse that is similar to tales and narrative. Storytelling is an ancient art, which is tackled in so many domains, from the study of ancient cultures to movie making, fiction writing and branding. Yet, it has never been 'hotter' than today. The principles and success factors are closely related with word of mouth marketing, social sharing; social media in general, brand perception and the very essence of content marketing and filmmaking. Describes the social and cultural activity of sharing stories, sometimes with improvisation, theatrics, or embellishment. Every culture has its own stories or narratives, which are shared as a means of entertainment, education, cultural preservation or instilling moral values. Crucial elements of stories and storytelling include plot, characters and narrative point of view, which is closely related to film structure and its script structure. So that, the term "storytelling" can refer in a narrow sense specifically to oral storytelling and in to techniques used in other media and film narrative of a story.

Keywords

Storytelling, Film Making, Script, Visual Narrative, Media.
\end{abstract}

\section{Introduction}

Storytelling can be defined as a set of artistic and aesthetic values, along with common visual language, enabling the same film art to build its real structure, which in turn positivly affects the film making and its scriptwriting.

Storytelling, visual narrative and film art embody our values, and define the basis of the good mental health of a society. These practices share in building an individual and collective sense and a kind of thinking/making which enables people to form and develop their identity.

\section{Nomenclature Reasons Behind Conducting This Research}

As an academic lecturer and practitioner of the film industry, especially the short animated film, we can easily notice the relationship between storytelling, narrative art and filmmaking, especially scriptwriting, noting also the direction of major universities around the world to study this relationship

Visual narrative/ Storytelling can be found in journalism, fiction films, young adult and children's books, comic books, internet and other forms. It is a graphic non-fiction and fiction for any audience. The courses come from both Creative Writing and Illustration.

Since Egypt has been and continues to assume a leading role in the film industry and in the teaching of art academically, in the Arab world, it is therefore necessary to shed more light on this relationship and how to develop it in favor of teaching and making film in Egypt and the Arab world.

*Corresponding author: info@pua.edu.eg 


\section{Research Aims}

The research aims to achieve the following:

Determine the relationship between the the art of storytelling and film making, especially scriptwriting and make a spot light in how to develop it.

\section{Research Methodology}

This paper utilizes a descriptive research methodology, specifically the theoretical documentary, based on collecting information from different sources of references including books or through the

\section{Subject}

\section{Storytelling}

Storytelling (narrative writing) is a method of communication based on a narrative structure of discourse that is similar to that of tales and narrative.

Storytelling is an ancient art which is very helpful in so many domains, from the study of ancient cultures to movie making, fiction writing and branding. Yet, it has never been 'hotter' than today. The principles and success factors are closely related with word of mouth marketing, social sharing, social media marketing in general, brand perception and the very essence of content marketing.

Describes the social and cultural activity of sharing stories, sometimes with improvisation, theatrics, or embellishment. Every culture has its own stories or narratives, which are shared as a means of entertainment, education, cultural preservation or instilling moralvalues. Crucial elements of stories and storytelling include plot, characters and narrative point of view.

The term "storytelling" can refer specifically to oral storytelling and to techniques used in other media to unfold or disclose the narrative of a story.

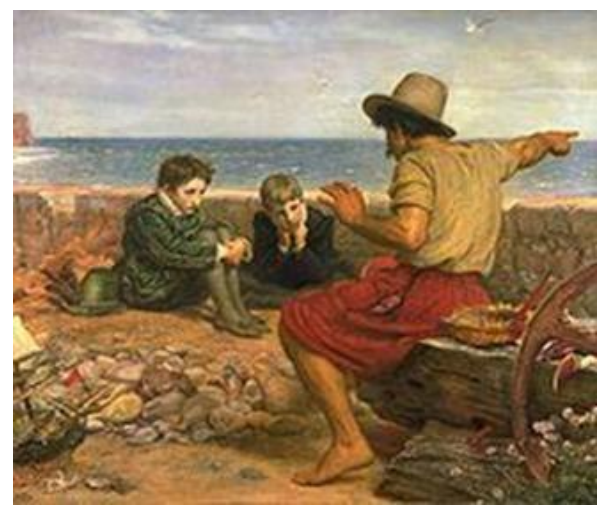

The Boyhood of Raleigh by Sir John Everett Millais, oil on canvas, 1870.

A seafarer tells the young Sir Walter Raleigh and his brother the story of what happened out at sea. 


\section{Oral traditions:}

Oral traditions of storytelling are found in several civilisations, they predate the printed and online press. Storytelling was used to explain natural phenomena, bards told stories of creation and developed a pantheon of gods and myths. Oral stories passed from one generation to the next and storytellers were regarded as healers, leader, spiritual guides, teachers, cutural secret keeper and entertainers. Oral storytelling came in various forms including songs, poetry, chants and dance.

\section{Contemporary storytelling:}

Modern storytelling has a broad purview. In addition to its traditional forms (fairytales, folktales, mythology, legends, fables etc.), it has extended itself to representing history, personal narrative, political commentary and evolving cultural norms. Contemporary storytelling is also widely used to address educational objectives. New forms of media are creating new ways for people to record, express and consume stories. Tools for asynchronous group communication can provide an environment for individuals to reframe or recast individual stories into group stories. Games and other digital platforms, such as those used in interactive fiction or interactive storytelling, may be used to position the user as a character within a bigger world. Documentaries, including interactive web documentaries, employ storytelling narrative techniques to communicate information about their topic. Self- revelatory stories, created for their cathartic and therapeutic effect, are growing in their use and application, as in Psychodrama, Drama Therapy and Playback Theatre.

\section{Emancipation of the story:}

In oral traditions, stories are kept alive by being told again and again. The material of any given story naturally undergoes several changes and adaptations during this process. When and where oral tradition was pushed back in favor of print media, the literary idea of the author as originator of a story's authoritative version changed people's perception of stories themselves. In centuries following, stories tended to be seen as the work of individuals rather than a collective effort. Only recently when a significant number of influential authors began questioning their own roles, the value of stories as such - independent of authorship - was again recognized.

\section{Storytelling as art form:}

The art of narrative is an aesthetic enterprise, and there are a number of artistic elements that typically interact in well-developed stories. Such elements include the essential idea of narrative structure with identifiable beginnings, middles, and endings, or expositiondevelopment-climax-resolution-denouement, normally constructed into coherent plot lines; a 
strong focus on temporality, which includes retention of the past, attention to present action and protention/future anticipation; a substantial focus on characters and characterization which is "arguably the most important single component of the novel"; a given heterogloss of different voices dialogically at play - "the sound of the human voice, or many voices, speaking in a variety of accents, rhythms and registers"; possesses a narrator or narrator-like voice, which by definition "addresses" and "interacts with" the audiences, a dialectic process of interpretation, which is at times beneath the surface, conditioning a plotted narrative, and at other times much more visible, "arguing" for and against various positions; relies substantially on now-standard aesthetic figuration, particularly including the use of metaphor, metonymy, synecdoche and irony ; is often enmeshed in intertextuality, with copious connections, references, allusions, similarities, parallels, etc. to other literatures; and commonly demonstrates an effort toward bildungsroman, a description of identity development with an effort to evince becoming in character and community.

\section{Visual Storytelling:}

Visual storytelling (and/or visual narrative) is "The art of communicating visually in forms that can be read or looked upon", visual storytelling emphasizes the expression of ideas and emotions through performance and aesthetics.

The process of visual storytelling often begins with the creation of storyboards - written or graphical progressions helpful in organizing and developing your concept. They are often used in digital creative and commercial ad planning to solidify your visuals as attention grabbing, logical and finished.

Successful visual stories are authentic, inspiring and humanistic. Many creative videos have gone viral due to embodying these traits and evoking influential emotions. "The Scarecrow", a companion film for Chipotle's app-based game promoting the importance of sustainable food, is just one high level example:

However, visual stories aren't only told by video. Print and photo campaigns often prove powerful in generating brand awareness and exposure for your cause.
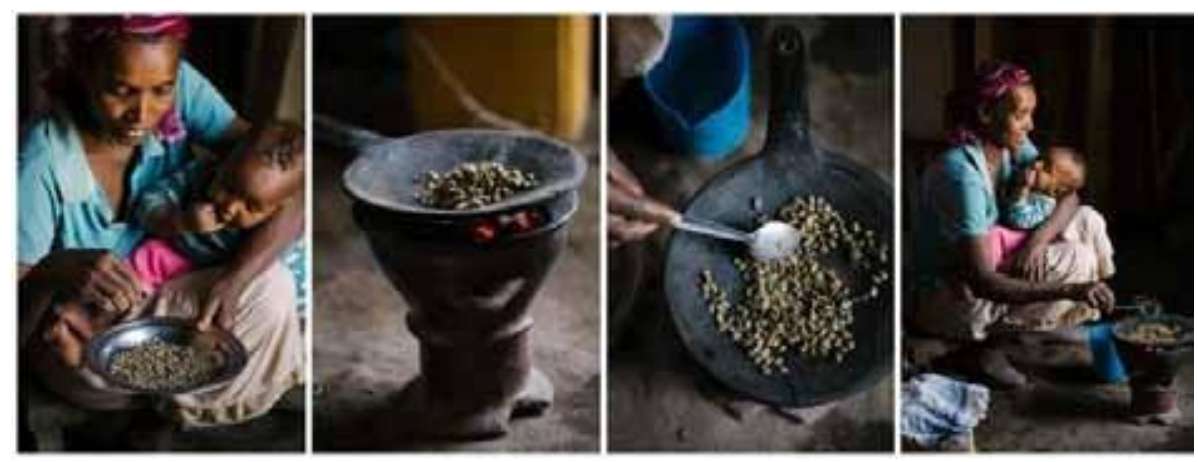
Images such as these are a great example of cohesive feature spreads that instill global, human connection

\section{Storytelling and persuasion:}

Storytelling used properly is one of the most effective techniques of persuasion. Sometimes, storytelling does not even need words. Visual story telling can include videos or even a billboard sign for advertising your product. Learning how to do this effectively is something that is a bloodline

\section{We are all storytellers:}

What makes a story great? What makes someone a good storyteller? Storytelling is something we all do naturally, starting at a young age, but there's a difference between good storytelling and great storytelling, that depends on the persuasion of storytelling.

\section{The Art of Persuasive Storytelling :}

"Your ability to shape your future depends on how well you communicate where you want to be when you get there. When ideas are communicated effectively, people follow and change." (by Nancy Duarte, Specialist of storytelling persuasion and communication expert) As a persuasion specialist, Nancy developed a unique methodology, which applies storytelling and visual thinking principles to business communications that shift audience beliefs and behaviors.

Durate says that presentations have the power to create change if they are communicated effectively and with empathy.

The Art of Persuasive Storytelling in its efinition is an attempt to evoke a change in the attitude and/or behavior of someone. A voluntary change. Not a command, threat, or coercion.

Aristotle's Rhetoric:

Logos: logical, coherent, cogent (clear) argument Ethos: the characteristics and credibility of the speaker

Pathos : the motives, feelings, attitudes, and knowledge of the audience

Agora: the context (where, when, timing, venue, culture) from Ancient Greece: a gathering place

\section{8 steps to delivering a persuasive presentation:}

1. Start with "What is" and compare it to "What could be"

The beginning of a great presentation starts with identifying "What is", the unappealing current status quo situation that the audience is in, and then takes them to "What could be", an appealing place where they want to go. You want the gap between what currently is and what could be to be as big as possible. The middle of the presentation moves back and forth between 
what is and what could be and is where you are trying to make the status quo seem unappealing in order to move the audience to your new idea. At the end of the presentation, you describe the new bliss.

\section{Be audience-centric}

You need to know who you are talking to if you are going to hit them with something that resonates. It's important to take the time to think through who the audience is and develop all your material from a place of empathy toward them. You're asking them to adopt your idea, which means they may have to abandon a belief they hold as true, by good preparation for your storytelling, your material will resonate and the audience can feel a deeper connection to you and your material.

3. Understand the role of the presenter - When giving a presentation, so many people feel like they're the central figure because they're the one talking the most. But in reality the audience is the hero - they determine if your idea lives or dies. Your role is that of a mentoryou should be giving the audience a magical gift or a special tool, or helping them get unstuck in some way. You have to defer to your audience. When you put your idea out there for an audience to contend with - if they reject your idea, your idea will die. You have to think of it as, "The storyteller needs the audience more than the audience needs the speaker." Then you'll start to approach a material with your audience in mind - you'll have more of a stance of humility than one of arrogance. That will help you create the kind of movement needed to get your idea to spread.

4. Wrap your content in a story - People want to remain in the status quo and getting them to move forward is like a bitter pill. Storytelling serves to make your audience feel that the goal can be reached and motivational stories help them to get there. If you look at preliterate generations for thousands and thousands of years, stories would pass down for generation after generation after generation and stay almost completely intact. Yet, a lot of people can't remember the last presentation they sat through. So, using principles of story the tension and release that happens in a story that's what will help persuade the audience toward your idea.

5. Be authentic - Great communication is a mix of honestly, passion and empathy which creates the need and desire for everyone to be a storyteller. Create and curate the stories that are already in your culture, they are already there, you just need to pluck them out and either redeem them of dismantle them.

6. Visualize someone you love - What you need to do right before telling a story, is think of someone that you love dearly." Doing this changes the chemistry in whole body. That feeling of affection in visualizing someone you love makes your body calm itself down. 
7. Rehearse. Rehearse. Rehearse. The power of rehearsing looks improvisational. The 200 hours spent in preparing for 18 minute presentationmake the presentation is very persuasive for the audience.

8. Use slides wisely / presentation- PowerPoint presentation or any other genre. The enemy of a great presentation is putting too much stuff on a presentationwhich is supposed to be a mnemonic device for the audience so they can remember what you had to say.

Presentation tools force you to think through information linearly, and you really need to start by thinking of the whole instead of the individual lines. Just work and work until the structure feels sound. And from that sound structure, you start to fill it in using a presentation tool.

\section{Four Elements of Performance:}

1. Style: Talk to a single individual; avoid hedges and disclaimers; keep stories focused, simple and direct; be yourself. Find a style that you're comfortable with.

2. Truth: Tell the truth as you see it; use caution in disclosing information about other people. 3. Prepare: Rehearse, but be spontaneous even if it's the 398th time you've told the story; choose the DESIGN of the story (backbone) and stick to it - add to it as audience responds; practice-practice -practice

4. Delivery: Storytelling is a performance art - be ready to perform; be lively (use voice inflection); connect with all parts of the audience (where does Obama look??); know your audience; connect with your audience. Remember to breath; use pauses for emphasis ... particularly around the key point of your story.

\section{Visual narrative:}

Visual Narrative (VN) is a term combined of the two words 'Visual' and 'Narrative'. It means that the distinctive feature of the $\mathrm{VN}$ is the presence of a story. Thus a VN must be a visual that tells a story. VN can be defined as a visual that essentially and explicitly narrates a story; where - Visual signifies - something that can be seen using the human eye.

Story signifies - a series of events linked by causality, temporality or sequence or the order of occurrence.

Narrative signifies - the act of telling a story or the story itself or the order of Presentation.

\section{Storytelling and visual narrative:}

Visual narrative (also visual storytelling) is a story told primarily through the use of visual media. The story may be told using still photography, illustration, or video, and can be enhanced with graphics, music, voice and other audio.

The term "visual narrative" has been used to describe several genres of visual storytelling, from news and information (photojournalism, the photo essay, the documentary film) to 
entertainment (art, movies, television, comic books, the graphic novel). In short, any kind of a story, told visually, is a visual narrative.

The visual narrative has also been of interest to the academic community as scholars, thinkers and educators have sought to understand the impact and power of image and narrative in individuals and societies. The corresponding discipline is called visual narratology.

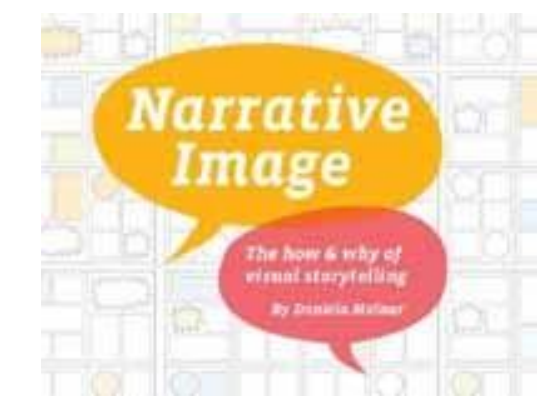

\section{Visual narrative and Storytelling}

\section{Narrative structure:}

Narrative structure, a literary element, is generally described as the structural framework that underlies the order and manner in which a narrative is presented to a reader, listener, or viewer. Narrative structure is about story and plot: the content of a story and the form used to tell the story. Story refers to the dramatic action as it might be described in chronological order.

Plot refers to how the story is told. Story is about trying to determine the key conflicts, main characters, setting and events. Plot is about how, and at what stages, the key conflicts are set up and resolved.

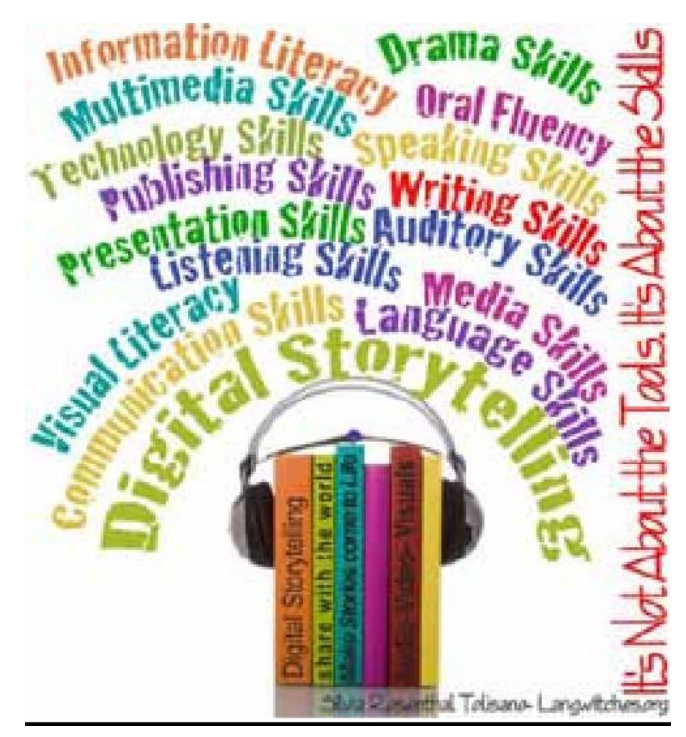




\section{Visual Narrative/ Storytelling}

\section{Description:}

The setup or act one, is where all of the main characters and their basic situations are introduced, and contains the primary level of characterization (exploring the character's backgrounds and personalities). A problem is also introduced, which is what drives the story forward.

The second act, the conflict, is the bulk of the story, and begins when the inciting incident (or catalyst) sets things into motion. This is the part of the story where the characters go through major changes in their lives as a result of what is happening; this can be referred to as the character arc, or character development.

The third act, or resolution, is when the problem in the story boils over, forcing the characters to confront it, allowing all the elements of the story to come together and inevitably leading to the ending.

\section{Film:}

Film, motion picture, theatrical film, or photoplay, is a series of still images that when shown on a screen create an illusion of motion images.

Films are cultural artifacts created by specific cultures. They reflect those cultures, and, in turn, affect them. Film is considered to be an important art form, a source of popular entertainment, and a powerful medium for educating or indoctrinating — citizens. The visual basis of film gives it a universal power of communication. Some films have become popular worldwide attractions by using dubbing or subtitles to translatethe dialog into the language of the viewer.

\section{Film Language and it relation with storytelling:}

Film is considered to have its own language, which captures life as a reflection, language understood by the audience. This describes another theory of film, as a visual story-telling device with an ability to place a viewer in a context of being psychologically present through the use of visual composition and editing of compositions that causes a time transition.

\section{Film grammar and its relation with storytelling:}

Major vs. minor beats/ Basic shot types/ Extreme shots/ Dynamics shots/ Storyboarding/ Advice/ feedback

The filmmaking team refines the films through the parts of their process called pitching and feedback. Pitching is the process of telling your story in very rough form, using script and storyboards or other rough imagery. After you pitch, you get feedback, which is basically hearing from the people you're pitching to what they liked and didn't like. This helps the storyteller assess what is working about their story, and what is not. This step is made as exactly 
a sort of storytelling and its feeback.

\section{Storytelling/ Film script dramatic Concept}

The meaning and dramatic structure that the story of a film should tell, changed from a film to another, exactly as in a storytelling where the story is changed from one story to another to change its dramatic concept.

\section{Film Script and Storytelling:}

A screenplay or script is a written work by screenwriters for a film, video game, or television program. These screenplays can be original works or adaptations from existing pieces of writing. In them, the movement, actions, expression, and dialogues of the characters are also narrated. A screenplay written for television is also known as a teleplay.

\section{Script sources:}

- Life, environment, society, personal experiences, literary novel, "reality, political issues and events, history, religions, theater, plastic art and others. Script sources Dramatic construction and division of work Beginning, middle and end, with the explanation of the dramatic node

\section{Stages of script writing:}

A. Summary or Synopsis main idea.

B. Situation:

C. Development and Conflict

D. Conclusion (Solution) Resolution:

E. Treatement

Image/ Sound

The relationship between image and sound in script writing is very important, they are equals in importance, complete each other in explaining the dramatic meaning

\section{Script and film elements:}

\section{Story structure:}

Every story that is told has a foundation, or structure. For example, one of the most basic story structures is "it begins, something happens, and it ends." But a story's structure can be complex, and if used well you're not even aware of it. In this lesson you'll learn how Pixar structures their films, and you'll start laying the foundation for your own stories.

The event

- $\quad$ The scene, place, time

The importance of understanding the role of space and time drama work 


\section{World, Decor/ Background; Characters:}

Introduction to character/ Warm up activity/ Internal vs. external features/ Wants vs. needs/ Obstacles/ Character arc/ Risks/ Advice Character; Characters are at the heart of every film, they're the individuals we follow on the journey of every story.

It is very important for a good script to:

- Understand the dimensions and psychological relationships and physical character. The psychological and physical relations of personalities and their relationship to each other

- Determine the Drama hero and secondary roles, the importance of explaining the relationships between characters and each other, the characters and their relationship to time and place

-The importance of understanding the dimensions and psychological and physical relationships of the characters and their relation to the place and time of work There are two basic rules for building character to create a good drama:

The first rule is that drama stems from personality. This means that the person around the film always determines the direction of the story. Thus, the plot is not merely a series of events that occur to a personality, but a series of events as a result of the choices made by the personality. The second rule is that the most important journey is that of the hero within himself. In the sense that whatever happens to the personality, the story will remain incomplete unless the personality is clearly changed as a result of its experiences.

But how do we apply these two rules to the story we want to tell?

The best way is to use a personal biography, a graphic line of characters.

A - Biography of the personality: Writing a mini autobiography of the main characters helps to identify the qualities and values of that character, which is embedded in the past of this character.

B - Character Chart: After the completion of the first draft, it is useful to make a graphic line for the appearance of characters in the viewer, which helps to know if the characters have evolved systematically and logically throughout the text. Structured recording also helps to analyze storytelling. 


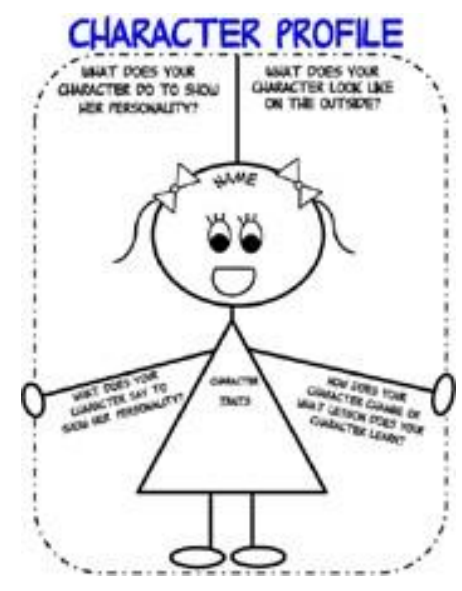

Character profile template

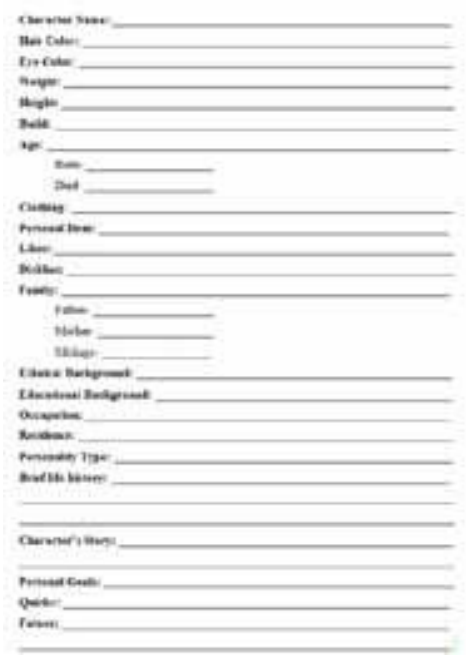

Character description

\section{Decor/ Background;}

"Decor" in film means all kinds of places or backgrounds, it can be a living room, a mountain range, or wide open spaces.

The importance of decoration produces from its relationship between the characters and events to location. Decor can reveal a forest, a library or a bedroom, so it should give a number of important facts. And more, it can be a luxury living room, simple, ugly or beautiful, oldfashioned or modern, revealing the richness or taste, and even about the period you are talking about.

\section{Decor and Character Accessory}

The accessory piece may be part of the decor, or part of the actor, and in both cases it reveals the character. There are accessories associated with certain events.. It is tempting to say that accessories take the place of character in the film. 
The narrator in storytelling may say "an elegant woman" and the screenwriter may show it in a coat of fur. The novelist may say "uncoordinated room." The screenwriter may display empty boxes on the floor.

- The language used and the vocabulary of the language according to the receiving audience, the dialogue reflects the social level, reflective of the political and social situation of society, reflective of the development and decline of language, when and why dialogue is used in the film of all kinds, when and why dialogue is used in the play.

\section{Similarities between Film script and Storytelling Structure:}

Beginning, Middle, and End

The structure of a short story or novel follows a pattern with a beginning, middle, and end. Each of the three parts of the story fulfills a distinct purpose.

The Beginning: Here the author hooks the reader by introducing the main characters and their goals, the setting, and the main conflict. The mood and tone are set at the beginning, and should be consistent throughout the story. The tension will fluctuate, but overall the tone should be suspenseful, romantic, or whatever, from start to finish.

The Middle: Here a series of events or complications occur, leading to an increase in the tension. This is also where the characters change and grow as they deal with the conflicts they face. Some of the minor crises are temporarily resolved, but the story continues in the direction of a major crisis, or climax.

The End: Here the main conflict is resolved, and the loose ends are tied up. Tension falls quickly, and a good ending leaves the readers satisfied - even if they aren't happy with the way things turned out.

This pattern is called the story arc; it can be visualized as an inverted check mark, with tension building to the climax, then abruptly declining. Depending on the type of story, the rise may be gradual or sharp, but the ending almost always comes shortly after the main climax. After all, the desire to see how the story ends is what keeps a reader (or viewer) continueng the story. Once they know how it works out, there is not much to hold their interest.

\section{Categories and schema:}

Establisher (E)

Sets up an interaction without acting upon it, often as a passive state Initial Initial (I)

Initiates the tension of the narrative arc, prototypically a preparatory action and/or a source of a path Peak $(\mathrm{P})$

Marks the height of narrative tension and point of maximal event structure, prototypically a completed action and/or goal of a path, but also often an interrupted action 
Release (R)

Releases the tension of the interaction, prototypically the coda or aftermath of an action From Visual Narrative Grammar to Filmic Narrative Grammar: The narrative structure of static and moving images.

\section{Canonical narrative schema}

[(Establisher $)-($ Initial $)-$ Peak - (Release $)]$

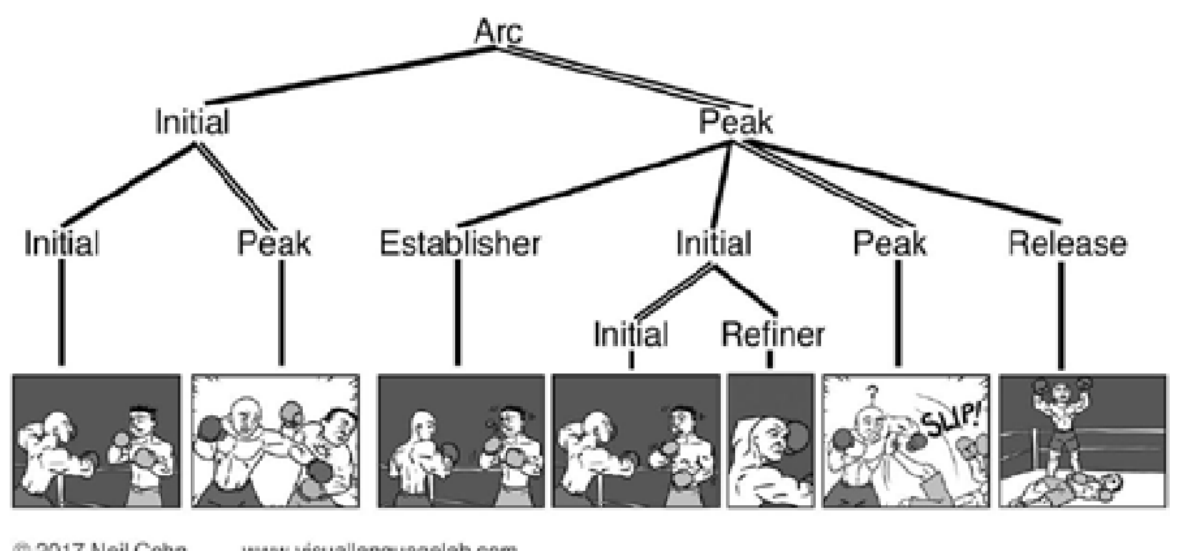

Similarities between Film script and Storytelling narrative categories

\section{Differences between Film script and Storytelling Scenes vs Chapters:}

- In a script, there are scenes.

- In a story, there are chapters.

\section{Imagination:}

- In a script, imagination has a small part to play.

- In a story, a lot is left to the imagination of the reader.

\section{Form:}

- A script is in dialogue form.

- A story is in prose form.

\section{Time:}

- A script is in the present.

- A story is not obligatory in the present.

\section{Narrative structure in film}

(The real relation between storytelling, Script \& film elements)

1. Narrative Structure in Film/ How Films Tell Stories

Narrative form is the structure though which movies tell stories. When we speak of 'going to 
the movies,' we almost always mean that we are going to see a narrative film - a film that tells a story.

2. Narratives appear everywhere ;

- throughout media and society I

common in fiction film, but appear in all basic types of film: Documentaries, Animated films, Experimental and avant-garde films, Short Films.

3. A narrative is an account of a string of events occurring in space and time.

-Narratives do not unfold randomly, but rather as an ordered series of events connected by the logic of cause and effect. This logic of cause and effect ties together character traits, goals, obstacles and actions. Events Occur in Space and Time.

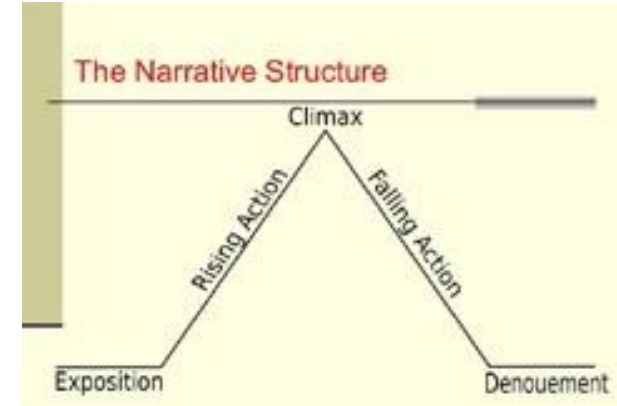

The Narrative Structure

\section{Narrative structure}

5. The Narrative Structure

- Exposition - meeting the characters, establishing the setting, setting the tone establishing the normal of the film world

-Rising Action - the central conflict is introduced and the tension between the protagonist and the antagonist begins to mount

-Climax - The climax is the turning point, which marks a change, for the better or the worse, in the protagonist's future.

- Falling Action - The major action has happened. This is the aftermath . This is the sorting out of the major conflict's resolution.

-Dénouement/Resolution - the creation of the new normal. The conflict is resolved

6. How narrative unfolds

-Typically a narrative begins with one situation (Exposition).

-A series of changes occurs according to a pattern of cause and effect.

- $\quad$ Finally a new situation arises - through character choice and conflict - that restores 
equilibrium to the world of the story and brings about the end of the narrative.

- $\quad$ The new story equilibrium almost always results in character change. How Narrative UnfoldsHow Narrative Unfolds

7. All begins with the protagonist (hero)

-Story changes that result from conflict and character choice force him into a climactic showdown with antagonist.

8. Character

- $\quad$ Narrative films generally focus on human characters and their struggles. Characters are typically responsible for cause and effect in narrative.

- Developing Characters How do writers develop round, dynamic characters?

-Through conversations with other characters Through group associations and through direct description of that character Through reactions to conflict

- $\quad$ Storytellers use different types of characters to tell their stories

- $\quad$ Flat: minor characters who do not go through any substantial change throughout the story or have much substance to them (think stereotypes)

- $\quad$ More fully developed characters who may experience a change during the story

- $\quad$ Character Traits

-Character Traits are attitudes, skills, habits, tastes, psychological drives and any other qualities that distinguish a character. Traits in opening scenes are relevant to later scenes; this is related to cause and effect.

- $\quad$ Character Choices and Goals

- Characters create cause and effect through choices that lead to conflict and consequences.

- $\quad$ These patterns are designed so that the viewer clearly sees and understands them.

- $\quad$ Characters posses traits, face conflicts, make choices and undergo changes that enable or hinder pursuit of a specific goal.

- $\quad$ Character Goals and obstacles

-Goals might include locating treasure, choosing a foster parent or looking for love.

- Characters encounter obstacles in pursuing these goals - the collision of goals and obstacles create conflict and thus drama.

9. Types of Conflicts Man v. Man.

Man v. Nature.

Man v. Himself: Man v. Society. Man v. Machine.

Man v. Supernatural. 
10. Diagetic vs. Nondiagetic Elements

- Diagetic elements are everything that exists in the world that the film depicts including everything implied offscreen: settings, sounds, characters, events.

- $\quad$ Nondiagetic elements are elements within the film, but not within the film's world, such as credits, music or voice-over narration.

- Characters are unaware of these elements.

- $\quad$ The Purpose of Nondiagetic Elements

The Purpose of Nondiagetic Elements "Filmmakers use non-diegetic elements for several reasons: they may draw attention to aspects of the narrative from a position outside the story, they communicate with the audience directly, and they engage viewers on an emotional level."

11. Selecting and Organizing Events

-Feature films have a running time or screen time of between 90 and 180 minutes. But the stories they tell rarely take place in that amount of time.

- $\quad$ In order to tell a story that may cover months or years, the filmmakers must choose to present certain events and leave others out.

11. The Story and the Plot

-The writer transforms a complete chronological story into an abbreviated, recognized version of events that plays out on the screen for the audience.

- $\quad$ Often the differences are referred to as story and plot.

- $\quad$ The Story

- $\quad$ The fabula is the chronological narrative, in its entirety.

- $\quad$ It include events that take place during the span of time of the plot that are implied but not overtly depicted.

- $\quad$ These include a character's backstory.

- $\quad$ The Plot

- $\quad$ The plot entails more than simply omitting events from the story

- it also involves reordering events - some times using flashbacks and flashforwards.

These are scenes from the past or future that interrupt the film's present tense to rearrange the chronology of the story.

- $\quad$ Repositioning events influences the way audiences understand them.

12. Selecting Events for Significance

"The distinction between the fabula and the Plot makes clear that each event represented in the film has been selected for dramatization and has been ordered systematically - there are no accidents . . . The Plot needs not chronicle every moment in the fabula, and it 
usually emphasizes the importance of some moments relative to others."

13. The End

The solution of the plot and end of events.

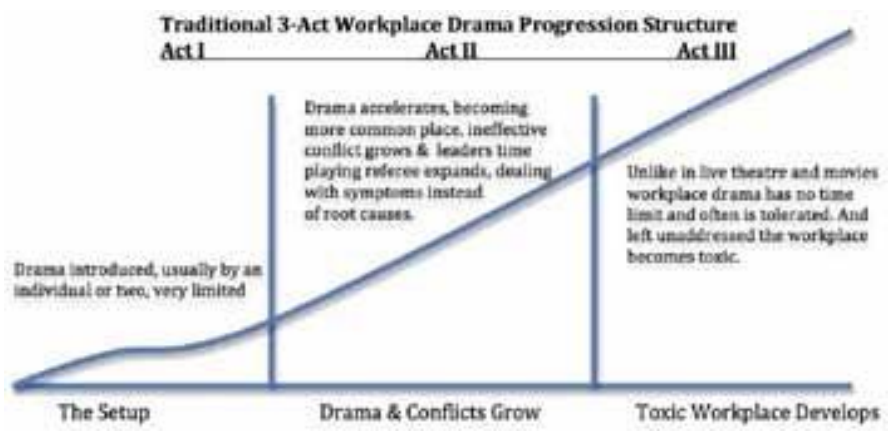

Traditional Film script and structure

The Basic Film Paradigm

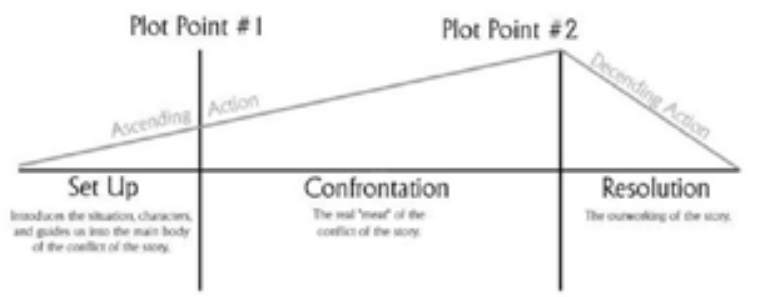

Narrative and Film script Paradigm

The Three Act Structure - diagram

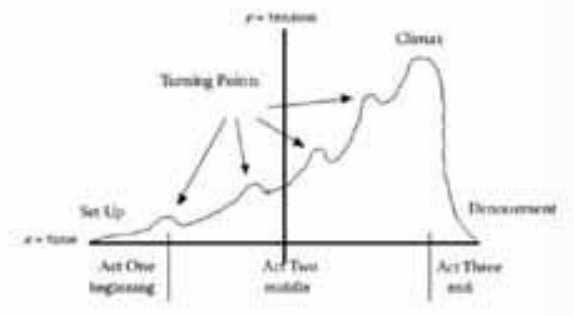

Three act structure diagram

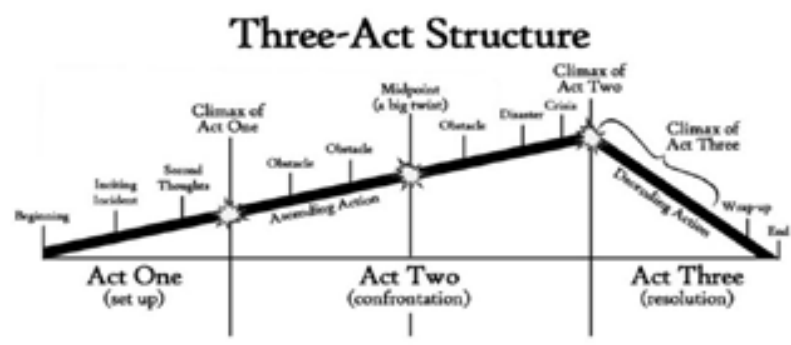

Film script and structure 


\section{Film and script principal genres:}

There are many genre and form of films and script writing, the most famous of them are the following kinds:

\section{Drama}

The word itself comes from the Greek word meaning 'action,' and it's with the Greeks and Romans that we start to define classical drama.

In film industry, drama refers to plays in general or to work that is connected with plays and the theatre, such as acting or producing.

In reference to film and television, drama is a genre of narrative fiction (or semi-fiction) intended to be more serious than humorous in tone.

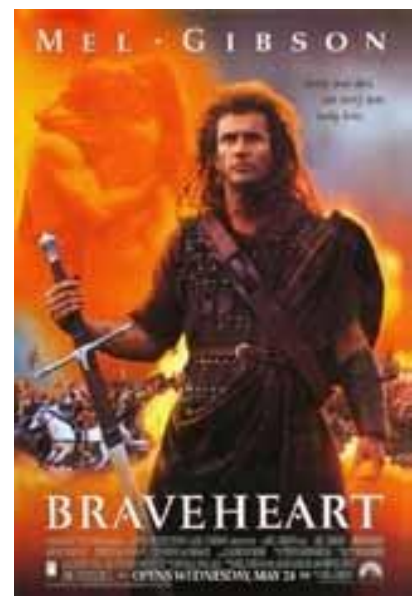

Drama film genre generates subtitles as action, comedy, musical and others.

\section{Animation}

Initially, films in this genre only consisted of movies done in 2D animation. As technology progresses and more and more computer generated films are coming out, the animation film genre is expanding its reach to clay animation, paper animation, stop motion animation and $2 \mathrm{D}$ \& 3D computer generated animation.

Animation film genre generates subtitles as 3D animation, Cut-out animation and others. 


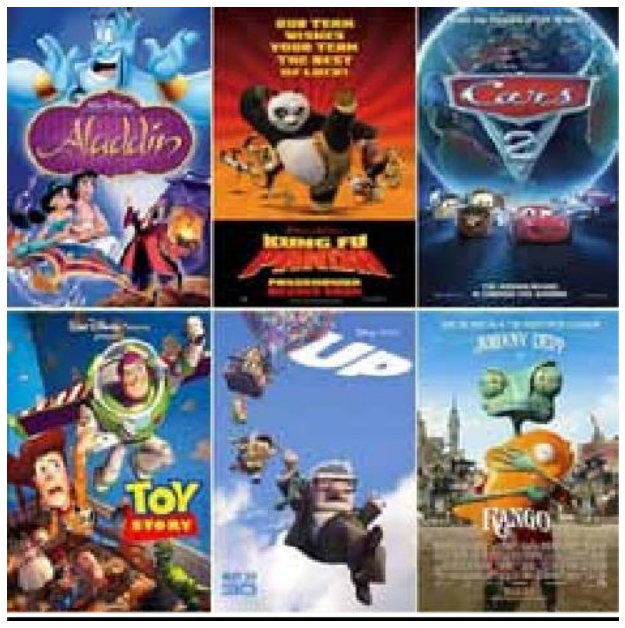

Animation films

\section{Documentary}

Documentary movies involve putting together real life events and people to tell a particular story. Film in this genre often involves a narrator, interviews and real footages of real events. They are done to execute social commentaries or to simply put historical events into a new light.

Documentary film genre generates subtitles as performance, participatory docudrama and others.

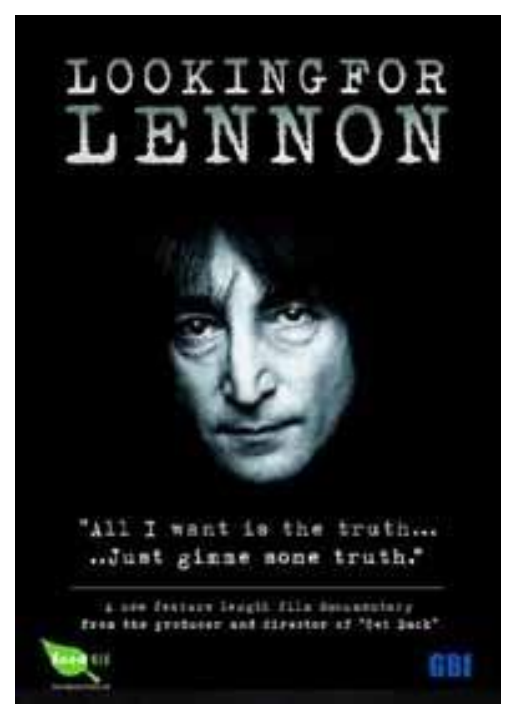

Documentary films 


\section{Conclusion}

The cinematic language played a large part of the global theoretical effort, because today's cinema has become a fused melting pot, in which all forms of human expression are mixed. It began to delve into many experimental fields through its openness to the arts, literature and others.

According to this concept, there is a strong relationship between the film and storytelling in particular, which emphasizes the importance of close bond between the storytelling and the film, This relationship is very much in the framework of what is known as visual narratives or a visual sotrytelling, which seeks to reveal the structure of the narrative of all narrative discourse, including film. Since the narration of the narrative in any narrative letter requires the existence of a narrator doing the narration (Script writer in film structure), and the existence of the material is the narrative itself and has been subject to the laws of narrative, in addition to the existence of a list of him receives the narrative so we have to recognize that:

First point: There is no narrative without Sard (apparent or hidden)

Moreover, any objective view of narrative discourse in general and film in particular requires us to say that the narrator as he narrates his story must be seen from a certain angle and there is a huge difference between the narrator narrates his story and has lived its real events in his personal capacity of his imagination. All that, necessarily leads to the secondpoint.

Second point: There is no prose without a point of view

The dialectical link between the first and the second leads us to the logical conclusion that: There is no narrative without a point of view. That is, there is no film without a point of view. The foregoing concepts lead to the need to address the narrative point of view and the importance of using the theoretical effort related to it in the field of narrative science, which leads us in this direction, But it makes us not unaware of the privacy of each narrative medium and the privacy of its requirements and then the privacy of the pattern of appearance of the view.

According to this view, the researcher had to take part in this film narrative approach, with a fundamental problem in mind, which is to identify a specific concept of the narrative perspective in the narrative film.

On the modern concepts of Visual storytelling or Visual narrative and based on the views of the most prominent theorists, especially with regard to the narrative perspective and its involvement in the film and its script. In addition, there is a contripution in pushing it forward and leads to increased mutual influence in order to ensure communication between them, while preserving the privacy of each narrative medium (Storytelling and Film script). This confirms 
the importance of the narrative point of view in the film, and this importance increases because we know that the point of view is not visible in the film Like other expressive elements (cinematic language) but rather a technique associated with the mode of presentation of events. That the process of addressing the concept of narrative point of view constitutes a fundamental basis for understanding the structure of visual narrative, storytelling in both the screenwriter in particular and filmmakers in general for the purpose of conveying the idea of drama work to the fullest, and that the narrative view forms the general framework governing the narrative stream, To give the artwork more value at the semantic level. In addition to the above, it is an important addition to the cinematic library and assigns cinematographers to perform their mission to the fullest.

\section{References}

1. Dynamic Video Narratives, Carlos D. Correa, Davis, Kwan-Liu Ma,University of California,Davis, Study, (seen 08/04/2017),

2. The thin line between propaganda and persuasion, Ryan Daniel Jenkins (seen 06/04/2017),

3. Visual Communication, Images with Messages, Eric Hoffer, 1902-1983; LONGSHOREMAN, AUTHOR, (seen 08/04/2017),

4. Narrative Visualization: Telling Stories with Data Edward Segel and Jeffrey Heer, Study, (seen3/02/2017)

5. Websitehttps://www.ted.com/talks/nancy_duarte_the_secret_structure_of_great_ talks, Study, (seen 07/02/2017)

6. Static Visual Narratives Visual Stories on Static Mediums by Sherline Pimenta K., Ph.D. Student IDC, IIT Bombay, Study, (seen 07/02/2017)

7. Seattle University School of Law Digital Commons Faculty Scholarship 2008 Storytelling, Narrative Rationality, and Legal Persuasion Chris Rideout, Study, (seen 07/02/2017)

How to analyze visual narratives: A tutorial in Visual Narrative Grammar, Study, (seen23/02/2017)

9. http://www.visuallanguagelab.com/P/VNG_Tutorial.pdf, (seen 23/02/2017)

10. https://twp.duke.edu/sites/twp.duke.edu/files/file-attachments/visualanalysis.original.pdf; (seen 23/03/2017) 11. http://www.uta.fi/yky/yhteystiedot/henkilokunta/mattikhyvarinen/index/Chap ter\%2026.pdf, (seen21/03/2017) 
12.

https://pdfs.semanticscholar.org/43f7/3341b52672c4d01a3521bb08c4874560

9477.pdf, (seen 18/02/2017)

13. http://www.edb.gov.hk/attachment/tc/curriculum-development/kla/arts

edu/pd/visual\%20communication.pdf (seen 23/04/2017)

14. https://blog.hubspot.com/marketing/visual-storytelling-examples, (seen $13 / 02 / 2017)$

15. https://www.shmoop.com/persuasion/narrator-point-of-view.html, (seen $13 / 02 / 2017)$

16. http://www.thevisuallinguist.com/2015/11/how-to-analyze-comics-withnarrative.html, (seen 19/02/2017)

17. https://awc.ashford.edu/tocw-persuasive.html, (seen 23/02/2017)

Received: February 10, 2018

Accepted: April 6, 2018 